\title{
Relationship between Cerebral Imaging and Executive Functions in Egyptian Elderly
}

\author{
Motassem S. Amer1, Nagia A. Fahmy², Sarah A. Hamza1, Eman F. Tash', \\ Mohammmad A. A. Allaboudy ${ }^{1}$ \\ ${ }^{1}$ Department of Geriatrics and Gerontology, Faculty of Medicine, Ain Shams University, Cairo, Egypt \\ ${ }^{2}$ Department of Neuropsychiatry, Faculty of Medicine, Ain Shams University, Cairo, Egypt \\ Email: hasarah 2000@yahoo.com
}

Received 13 February 2014; revised 7 April 2014; accepted 23 April 2014

Copyright (C) 2014 by authors and Scientific Research Publishing Inc.

This work is licensed under the Creative Commons Attribution International License (CC BY). http://creativecommons.org/licenses/by/4.0/

c) (7) Open Access

\begin{abstract}
This study aimed at assessing the relationship between executive functions and left sided hemiplegia due to non hemorrhagic supratentorial infarction in elderly Egyptians. It is considered a case control study which was conducted among 90 elderly participants, who were divided into two groups: a case group, 45 cases with cerebral infarctions of 6 months duration or more, and a control group who did not have previous cerebral infarctions. Both groups were selected from Ain shams University Hospital. Each participant was subjected to comprehensive geriatric assessment, executive functions assessment using, block design test, digit span, letter verbal fluency test, animal verbal fluency test and clock drawing test, and then a Computed Tomography (CT) brain was performed. It was found that cases were suffering from more functional impairment than controls, and have had significant lower scores in Mini Mental Status Examination (MMSE) $(P<0.01)$. Significant difference was found between both groups as regards performance of executive function tests $(P<0.05)$. Significant effect of Parietal lobe infarctions was found on Block Design Test, Digit Span Test, Animal Verbal Fluency and Clock Drawing Test ( $P$ value $<0.05)$. Conclusion: There was a significant difference between cases and controls as regards their performance in cognitive and executive function tests.
\end{abstract}

\section{Keywords}

Executive Functions, Cerebral Infarctions, Elderly

\section{Introduction}

The prevalence of executive impairment is high and it is common among medical inpatients [1]. The failure to 
identify medically ill patients with executive impairments could have important clinical consequences, especially with regard to medication adherence, preservation of autonomy, relapse prevention, post discharge placement, and potential for rehabilitation [2].

Cerebral infarction is the second most common cause of cognitive impairment and dementia. The accumulation of lacunar infarcts, ischemic white matter disease and cerebral hypoperfusion are the most common causes of cognitive impairment/dementia due to cerebral infarction that can go unrecognized. Infarctions predominantly affect the connections between areas of cortex that associate complex types of information, the disruption of which leads to impaired cognition and function. Larger infarctions are usually detected clinically and cognitive impairment is thus more likely to be detected early. Detecting infarctions early allows initiation of the appropriate treatment that can prevent or substantially delay the onset and progression of cognitive impairment [3]-[7].

The most common types of cognitive deficits arising from cerebral infarction are disturbances of attention, language syntax, delayed recall and executive dysfunction affecting the ability to analyze, interpret, plan, organize, and execute complex information [8]-[11].

This study aimed to assess the relationship between cerebral infarctions and executive functions in the elderly.

\section{Method}

The study is a case control study, which was conducted among 90 elderly subjects, who were 60 years old or elder males and females. They were divided into two groups: Group A (case group): 45 cases who had cerebral infarctions of 6 months duration or more, and Group B (control group) 45 controls who did not have previous cerebral infarctions, but have other co morbidities matched to those of controls. Both groups 1 and 2 were selected from hospitalized patients and those attending outpatient clinics in Ain shams University Hospital. An informed consent was taken from all participants. A comprehensive geriatric and neurological assessment was done. Tests to assess executive function were also performed.

Mental state assessment was performed using the mini mental status examination (MMSE) for assessment of cognitive function [12] with its Arabic version [13]. Functional assessment was performed by: Activities of Daily Living (ADL) [14] and Instrumental Activities of Daily Living (IADL) [15]. Assessment of executive functions was assessed by multiple tests; Arabic version of Block design test [16] [17], Arabic version of Digit span (forward and backward) [16] [17], Letter verbal fluency test [18], Animal verbal fluency test [19], and Clock drawing test [20]. Then, every participant was subjected to a Computed Tomography (CT) brain.

After that, collection of result and statistical analysis were performed by using the $13^{\text {th }}$ version of Statistical Package for Social Science (SPSS). Description of all data in the form of mean (M) and standard deviation (SD) for all quantitative variables was done. Frequency and percentage for all qualitative variables were calculated. Comparison between quantitative variables was done using t-test to compare two groups. Comparison of qualitative variables was done using the Chi-square test. Significant level measured according to P value (probability), and $\mathrm{P}<0.05$ is significant.

\section{Results}

Cases and controls were matched as regards mean age (65.311 \pm 6.8 years in cases, $65.244 \pm 5.4$ years in controls $\mathrm{P}=0.07)$. Similarly they were matched as regards sex $(51 \%$ males and $49 \%$ females in cases and $56 \%$ males and $44 \%$ females in control group $\mathrm{P}=0.6$ ).

Thirty-four cases had single cerebral infarctions, eight cases had two attacks of cerebral infarctions, and 3 had three attack or more.

Table 1 shows the localizations of different infarctions in cerebral hemispheres.

As regards neurological deficits $91 \%$ of cases were suffering from residual motor neurological deficit, and $71 \%$ were suffering from sensory neurological deficit.

A comparison between cases and controls as regards comorbid medical conditions was demonstrated in Table 2 .

Cases were suffering from more functional impairment than controls as regards ADL and IADL $(\mathrm{P}<0.05)$. Additionally cases were having significant lower scores in MMSE (26.622 \pm 3 in cases and $29.20 \pm 0.9$ in controls $\mathrm{P}<0.01$ ).

Figure 1 shows that cases had significant abnormal performance in Block Design Test, Animal Verbal Fluency Test, and Clock Drawing Test more than controls (P value $<0.05$ ). Meanwhile, comparison between the two groups as regards performance in executive functions was demonstrated in Table 3. 
Table 1. Anatomical site of CVS in the CNS among cases.

\begin{tabular}{lcc}
\hline Site of Cerebral Infarctions in Cases & N & $\%$ \\
\hline Parietal & 14 & 31.11 \\
Temporal & 7 & 15.56 \\
Occipital & 4 & 8.89 \\
Capsular & 12 & 26.67 \\
Thalamic, BG (Basal Ganglia) & 10 & 22.22 \\
Periventricular & 7 & 15.56
\end{tabular}

Table 2. Comparison between cases and controls as regards different co morbidities.

\begin{tabular}{|c|c|c|c|c|c|c|c|c|c|}
\hline & & \multicolumn{8}{|c|}{ Groups } \\
\hline & & \multicolumn{2}{|c|}{ Cases } & \multicolumn{2}{|c|}{ Control } & \multicolumn{2}{|c|}{ Total } & \multicolumn{2}{|c|}{ Chi-square } \\
\hline & & $\mathrm{N}$ & $\%$ & $\mathrm{~N}$ & $\%$ & $\mathrm{~N}$ & $\%$ & $X^{2}$ & P-value \\
\hline \multirow{2}{*}{ DM } & Yes & 22 & 48.89 & 13 & 28.89 & 35 & 38.89 & \multirow{2}{*}{2.992} & \multirow{2}{*}{0.084} \\
\hline & No & 23 & 51.11 & 32 & 71.11 & 55 & 61.11 & & \\
\hline \multirow{2}{*}{ HTN } & Yes & 33 & 73.33 & 26 & 57.8 & 59 & 65.56 & \multirow{2}{*}{1.771} & \multirow{2}{*}{0.183} \\
\hline & No & 12 & 26.67 & 19 & 42.2 & 31 & 34.44 & & \\
\hline \multirow{2}{*}{ IHD } & Yes & 14 & 31.11 & 12 & 26.7 & 26 & 28.89 & \multirow{2}{*}{0.054} & \multirow{2}{*}{0.816} \\
\hline & No & 31 & 68.89 & 33 & 73.3 & 64 & 71.11 & & \\
\hline \multirow{2}{*}{$\mathrm{HF}$} & Yes & 9 & 20.00 & 9 & 20.00 & 18 & 20.00 & \multirow{2}{*}{0.000} & \multirow{2}{*}{1.00} \\
\hline & No & 36 & 80.00 & 36 & 80.00 & 72 & 80.00 & & \\
\hline \multirow{2}{*}{$\mathrm{AF}$} & Yes & 6 & 13.33 & 2 & 4.44 & 8 & 8.89 & \multirow{2}{*}{2.195} & \multirow{2}{*}{0.138} \\
\hline & No & 39 & 86.67 & 43 & 95.56 & 82 & 91.11 & & \\
\hline \multirow{2}{*}{ PVD } & Yes & 3 & 6.67 & 1 & 2.2 & 4 & 4.44 & \multirow{2}{*}{1.047} & \multirow{2}{*}{0.306} \\
\hline & No & 42 & 93.33 & 44 & 97.8 & 86 & 95.56 & & \\
\hline \multirow{2}{*}{ COPD } & Yes & 5 & 11.11 & 11 & 24.44 & 16 & 17.78 & \multirow{2}{*}{1.900} & \multirow{2}{*}{0.1680} \\
\hline & No & 40 & 88.89 & 34 & 75.56 & 74 & 82.22 & & \\
\hline \multirow{2}{*}{ BA } & Yes & 3 & 6.67 & 6 & 13.33 & 9 & 10.00 & \multirow{2}{*}{1.111} & \multirow{2}{*}{0.292} \\
\hline & No & 42 & 93.33 & 39 & 86.67 & 81 & 90.00 & & \\
\hline \multirow{2}{*}{$\mathrm{PU}$} & Yes & 3 & 6.67 & 1 & 2.2 & 4 & 4.44 & \multirow{2}{*}{1.047} & \multirow{2}{*}{0.306} \\
\hline & No & 42 & 93.33 & 44 & 97.8 & 86 & 95.56 & & \\
\hline & Yes & 4 & 8.89 & 6 & 13.3 & 10 & 11.11 & & \\
\hline CLD & No & 41 & 91.11 & 39 & 86.7 & 80 & 88.89 & 0.450 & 0.502 \\
\hline & Yes & 5 & 11.11 & 1 & 2.22 & 6 & 6.67 & & \\
\hline $\mathrm{KF}$ & No & 40 & 88.89 & 44 & 97.78 & 84 & 93.33 & $2.05 /$ & 0.091 \\
\hline
\end{tabular}

(DM = Diabetes Mellitus, HTN = Hypertension, IHD = Ischemic Heart Disease, HF = Heart Failure, AF = Atrial Fibrillation, PVD = Peripheral Vascular Disease, COPD = Chronic Obstructive Pulmonary Disease, BA = Bronchial Asthma, PU = Peptic Ulcer, CLD = Chronic Liver Disease, RF = Renal Failure).

Studying the effect of the site of cerebral infarctions on the executive functions revealed significant effect of Parietal lobe infarctionson Block Design Test, Digit Span Test, Animal Verbal Fluency, and Clock Drawing Test $(\mathrm{P}$ value $<0.05$ ) and significant effect of Temporal lobe infarctions on Block Design Test, Animal Verbal Fluency and Clock Drawing Test, (P value $<0.05$ ). No significant effect of Capsular infarctions on executive function tests (P value $>0.05$ ) but significant effect of Thalamic and Basal Ganglia infarctionson Block Design Test, and Animal Verbal Fluency Test $(P$ value $<0.05)$ and significant effect of Periventricular infarctions on Block Design Test (P value < 0.05) (Table 4). 


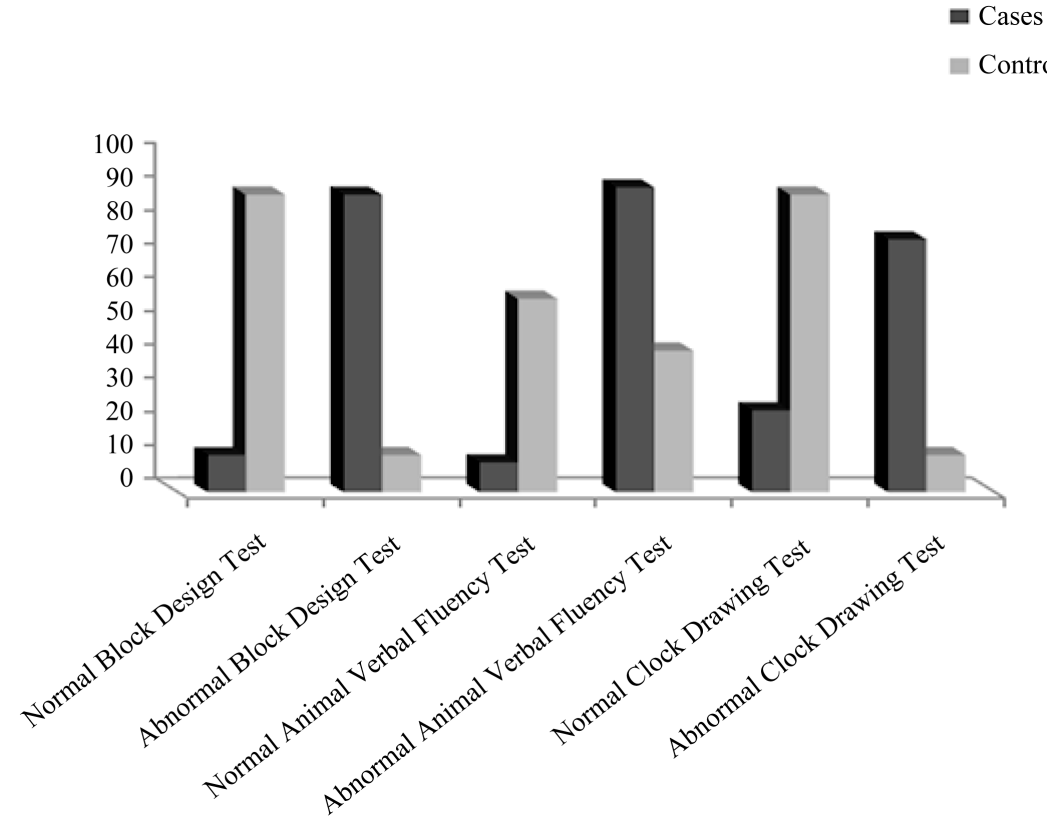

Figure 1. Comparison between cases and controls as regards abnormal performance in block design test, animal verbal fluency test, and clock drawing test.

Table 3. Comparison between the two groups as regards performance in executive functions.

\begin{tabular}{|c|c|c|c|c|}
\hline Block design & Range & Mean & $\mathrm{T}$ & $\mathrm{P}$ \\
\hline Cases & $0-16$ & $3.244 \pm 4.024$ & \multirow{2}{*}{-11.102} & \multirow{2}{*}{$0.000^{*}$} \\
\hline Control & $0-23$ & $12.644 \pm 4.734$ & & \\
\hline \multicolumn{5}{|l|}{ Digit Span Test } \\
\hline Cases & $3-12$ & $7.400 \pm 1.864$ & \multirow{2}{*}{-4.095} & \multirow{2}{*}{$0.000^{*}$} \\
\hline Controls & $4-15$ & $8.933 \pm 1.684$ & & \\
\hline \multicolumn{5}{|c|}{ Letter Verbal Fluency Test } \\
\hline Cases & $0-11$ & $3.222 \pm 2.819$ & \multirow{2}{*}{-2.592} & \multirow{2}{*}{$0.005^{*}$} \\
\hline Controls & $0-13$ & $5.022 \pm 3.708$ & & \\
\hline \multicolumn{5}{|c|}{ Animal Verbal Fluency Test } \\
\hline Cases & $2-14$ & $7.600 \pm 3.078$ & \multirow{2}{*}{-7.290} & \multirow{2}{*}{$0.000^{*}$} \\
\hline Controls & $8-23$ & $11.955 \pm 2.566$ & & \\
\hline \multicolumn{5}{|c|}{ Clock Drawing Test } \\
\hline Cases & $0-7$ & $5.200 \pm 2.777$ & 9.323 & $0.000^{*}$ \\
\hline
\end{tabular}

N.B. ${ }^{*}=$ significant.

\section{Discussion}

The purpose of this study is to assess the relationship between cerebral infarctions and executive functions in elderly. Both groups were matched regarding age, sex and comorbid conditions.

Comparing both groups as regards mental, functional and executive functions revealed that cases had significantly lower performance than controls. This study agreed with previous studies [11] [21]-[23], taking in consideration the wide range of different neuropsychological batteries used for assessment of cognitive/executive functions in each study. This supports our hypothesis that the effect of cerebral infarctions on executive functions should be considered among patients with a history of cerebral infarctions.

Among cases group, the effect of the location of cerebral infarctions (diagnosed by neurological imaging as CT Brain) on different cognitive and executive functions tests was studied. It was found that there was a significant negative effect of Parietal lobe infarctionson Block Design Test, Digit Span Test, Animal Verbal Fluency, 
Table 4. Effect of different sites of cerebral infarctionson executive function tests.

\begin{tabular}{|c|c|c|c|c|c|}
\hline \multirow{2}{*}{ Site of Cerebral Infarctions } & \multirow{2}{*}{ Executive function tests } & No & Yes & \multirow{2}{*}{$\mathrm{T}$} & \multirow{2}{*}{ P-value } \\
\hline & & Mean \pm SD & Mean \pm SD & & \\
\hline \multirow{5}{*}{ Parietal infarctions } & Block Design Test & $9.105 \pm 6.513$ & $1.714 \pm 2.268$ & 4.183 & $0.000^{*}$ \\
\hline & Digit Span Test & $8.408 \pm 1.927$ & $7.071 \pm 1.774$ & 2.412 & $0.018^{*}$ \\
\hline & Letter Verbal Fluency & $4.434 \pm 3.782$ & $3.429 \pm 2.409$ & 0.957 & 0.341 \\
\hline & Animal Verbal Fluency & $10.684 \pm 3.549$ & $6.143 \pm 2.878$ & 4.516 & $0.000^{*}$ \\
\hline & Clock Drawing Test & $2.513 \pm 3.223$ & $6.071 \pm 1.730$ & -4.013 & $0.000^{*}$ \\
\hline \multirow{5}{*}{ Temporal infarctions } & Block Design Test & $8.482 \pm 6.593$ & $1.714 \pm 2.360$ & 2.689 & $0.009^{*}$ \\
\hline & Digit Span Test & $8.301 \pm 1.980$ & $7.000 \pm 1.155$ & 1.709 & 0.091 \\
\hline & Letter Verbal Fluency & $4.398 \pm 3.705$ & $2.857 \pm 1.773$ & 1.085 & 0.281 \\
\hline & Animal Verbal Fluency & $10.265 \pm 3.752$ & $6.571 \pm 2.992$ & 2.533 & $0.013^{*}$ \\
\hline & Clock Drawing Test & $2.831 \pm 3.298$ & $5.857 \pm 1.676$ & -2.393 & $0.019^{*}$ \\
\hline \multirow{5}{*}{ Occipital infarctions } & Block Design Test & $8.221 \pm 6.627$ & $2.250 \pm 2.872$ & 1.786 & 0.077 \\
\hline & Digit Span Test & $8.291 \pm 1.939$ & $6.250 \pm 1.258$ & 2.078 & $0.041^{*}$ \\
\hline & Letter Verbal Fluency & $4.384 \pm 3.630$ & $2.000 \pm 2.449$ & 1.296 & 0.198 \\
\hline & Animal Verbal Fluency & $10.093 \pm 3.821$ & $7.500 \pm 3.109$ & 1.334 & 0.186 \\
\hline & Clock Drawing Test & $2.930 \pm 3.289$ & $6.000 \pm 2.000$ & -1.845 & 0.068 \\
\hline \multirow{5}{*}{ Capsular infarctions } & Block Design Test & $8.436 \pm 6.772$ & $4.833 \pm 4.549$ & 1.778 & 0.079 \\
\hline & Digit Span Test & $8.218 \pm 1.998$ & $8.083 \pm 1.730$ & 0.221 & 0.826 \\
\hline & Letter Verbal Fluency & $4.308 \pm 3.619$ & $4.083 \pm 3.704$ & 0.199 & 0.842 \\
\hline & Animal Verbal Fluency & $10.128 \pm 3.922$ & $9.000 \pm 2.985$ & 0.953 & 0.343 \\
\hline & Clock Drawing Test & $2.821 \pm 3.226$ & $4.667 \pm 3.447$ & -1.829 & 0.071 \\
\hline \multirow{5}{*}{ Thalamic and BG infarctions } & Block Design Test & $8.713 \pm 6.574$ & $1.900 \pm 2.726$ & 3.229 & $0.002^{*}$ \\
\hline & Digit Span Test & $8.338 \pm 1.889$ & $7.100 \pm 2.234$ & 1.915 & 0.059 \\
\hline & Letter Verbal Fluency & $4.538 \pm 3.707$ & $2.200 \pm 1.687$ & 1.961 & 0.053 \\
\hline & Animal Verbal Fluency & $10.325 \pm 3.808$ & $7.200 \pm 2.658$ & 2.513 & $0.014^{*}$ \\
\hline & Clock Drawing Test & $2.838 \pm 3.235$ & $4.900 \pm 3.381$ & -1.892 & 0.062 \\
\hline \multirow{5}{*}{ Periventricular infarctions } & Block Design Test & $8.386 \pm 6.615$ & $2.857 \pm 4.259$ & 2.167 & $0.033^{*}$ \\
\hline & Digit Span Test & $8.229 \pm 1.896$ & $7.857 \pm 2.734$ & 0.481 & 0.632 \\
\hline & Letter Verbal Fluency & $4.494 \pm 3.654$ & $1.714 \pm 1.604$ & 1.988 & 0.050 \\
\hline & Animal Verbal Fluency & $10.193 \pm 3.874$ & $7.429 \pm 1.618$ & 1.866 & 0.065 \\
\hline & Clock Drawing Test & $2.940 \pm 3.299$ & $4.571 \pm 3.101$ & -1.261 & 0.210 \\
\hline
\end{tabular}

N.B. ${ }^{*}=$ significant.

and Clock Drawing Test. There was also a significant negative effect of Temporal lobe infarctionson Block Design Test, Animal Verbal Fluency, and Clock Drawing Test. As regards Occipital lobe infarctions, it had a significant negative effect on Digit Span Test. There was also a significant negative effect of Thalamic and Basal Ganglia infarctionson Block Design Test, and Animal Verbal Fluency Test. Periventricular infarctions had significant negative effect on Block Design Test.

It was apparent that Parietal lobe infarctions, Temporal lobe infarctions and Thalamic and Basal Ganglia infarctions had the highest significant effect on different cognitive and executive function tests This can support the results of previous studies [24]-[26]. These results can introduce several research questions about the relation between the site of stoke and its cognitive and executive effects.

The current study spot light on the importance on assessing executive functions on multiple categories of patients; patients with previous history of cerebral infarctions or transient ischemic attacks, and elderly having risk 
factors for cerebral infarctions.

It should be considered as a part of comprehensive assessment of elderly patients especially who are at risk to develop cerebral infarctions or with previous history.

Further studies especially cohort ones are needed to confirm the value of assessment of executive functions.

The effect on executive functions has a serious impact on the functional capacity and quality of life.

\section{Conclusion}

There was a significant difference between cases and controls as regards their performance in cognitive and executive function tests. The case group showed impaired performance in all the tests in the battery including MMSE. Additionally there is a positive relationship between executive dysfunction with left sided hemiplegia due to non hemorrhagic supratentorial infarction in the elderly.

\section{References}

[1] Schillerstrom, J.E., Horton, M.S., Schillerstrom, T.L., Joshi, K.G., Earthman, B.S., Velez, A.M. and Royall, D.R. (2005) Prevalence, Course, and Risk Factors for Executive Impairment in Patients Hospitalized on a General Medicine Service. Psychosomatics, 46, 411-417. http://dx.doi.org/10.1176/appi.psy.46.5.411

[2] Schillerstrom, J.E., Horton, M.S. and Royall, D.R. (2005) The Impact of Medical Illness on Executive Function. Psychogeriatrics, 46, 508-516.

[3] Mok, V., Chang, C., Wong, A., Lam, W.W., Richards, P.S., Wong, K.T. and Wong, K.S. (2005) Neuroimaging Determinants of Cognitive Performances in Stroke Associated with Small Vessel Disease. Journal of Neuroimaging, 15, 129-137. http://dx.doi.org/10.1177/1051228404274304

[4] Mok, V., Wong, A., Tang, W.K., Lam, W.W., Fan, Y.H., Richards, P.S., Wong, K.T., Ahuja, A.T. and Wong, K.S. (2005) Determinants of Prestroke Cognitive Impairment in Stroke Associated with Small Vessel Disease. Dementia and Geriatric Cognitive Disorders, 20, 225-230. http://dx.doi.org/10.1159/000087310

[5] Mok, V.C., Wong, A., Lam, W.W., Fan, Y.H., Tang, W.K., Kwok, T., Hui, A.C. and Wong, K.S. (2004) Cognitive Impairment and Functional Outcome after Stroke Associated with Small Vessel Disease. Journal of Neurology, Neurosurgery \& Psychiatry, 75, 560-566. http://dx.doi.org/10.1136/jnnp.2003.015107

[6] Wen, H.M., Mok, V.C., Fan, Y.H., Lam, W.W., Tang, W.K., Wong, A., Huang, R.X. and Wong, K.S. (2004) Effect of White Matter Changes on Cognitive Impairment in Patients with Lacunar Infarcts. Stroke, 35, 1826-1830. http://dx.doi.org/10.1161/01.STR.0000133686.29320.58

[7] Wong, A., Mok, V., Fan, Y.H., Lam, W.W., Liang, K.S. and Wong, K.S. (2005) Hyperhomocysteinemia Is Associated with Volumetric White Matter Change in Patients with Small Vessel Disease. Journal of Neurology, 253, 441-447.

[8] Jokinen, H., Kalska, H., Mantyla, R., Pohjasvaara, T., Ylikoski, R., Hietanen, M., Salonen, O., Kaste, M. and Erkinjuntti, T. (2006) Cognitive Profile of Subcortical Ischaemic Vascular Disease. Journal of Neurology, Neurosurgery \& Psychiatry, 77, 28-33. http://dx.doi.org/10.1136/jnnp.2005.069120

[9] Lindeboom, J. and Weinstein, H. (2004) Neuropsychology of Cognitive Ageing, Minimal Cognitive Impairment, Alzheimer's Disease, and Vascular Cognitive Impairment. European Journal of Pharmacology, 490, 83-86. http://dx.doi.org/10.1016/j.ejphar.2004.02.046

[10] Nyenhuis, D.L., Gorelick, P.B., Geenen, E.J., Smith, C.A., Gencheva, E., Freels, S. and deToledo-Morrell, L. (2004) The Pattern of Neuropsychological Deficits in Vascular Cognitive Impairment-No Dementia (Vascular CIND). Clinical Neuropsychology, 18, 41-49. http://dx.doi.org/10.1080/13854040490507145

[11] Sachdev, P.S., Brodaty, H., Valenzuela, M.J., Lorentz, L., Looi, J.C., Wen, W. and Zagami, A.S. (2004) The Neuropsychological Profile of Vascular Cognitive Impairment in Stroke and TIA Patients. Neurology, 62, 912-919. http://dx.doi.org/10.1212/01.WNL.0000115108.65264.4B

[12] Folstein, M.F., Folstein, S.E. and McHugh, P.R. (1975) Mini-Mental State: A Practical Method for Grading the State of Patients for the Clinician. Journal of Psychiatric Research, 12, 189-198. http://dx.doi.org/10.1016/0022-3956(75)90026-6

[13] El-Okl, M.A. (2002) Prevalence of Alzheimer Dementia and Other Causes of Dementia in Egyptian Elderly. MD Thesis, Faculty of Medicine, Ain Shams University, Cario.

[14] Katz, S., Ford, A.B., Moskowitz, R.W., Jackson, B.A. and Jaffe, M.W. (1963) Studies of Illness in the Aged. The Index of ADL, a Standardized Measure of Biological and Psychosocial Function. JAMA, 185, 914-919. http://dx.doi.org/10.1001/jama.1963.03060120024016

[15] Lawton, M.P. and Brody, E.M. (1969) Assessment of Older People: Self-Maintaining and Instrumental Activities of 
Daily Living. Gerontologist, 9, 179-186.

[16] Wechsler, D. (1981) Wechsler Adult Intelligence Scale (WAIS-R) Manual. The Psychological Coro, New York.

[17] Melika, L.K. (1991) Wechsler Intelligence Scale for Adults and Adolescents. Cairo El-Nahda Egyptian Library, 91, 92, $97 \& 101$.

[18] Gladsjo, J.A., Miller, S.W. and Heaton, R.K. (1999) Norms for Letter and Category Fluency: Demographic Correction for Age, Education and Ethnicity. Psychlogical Assessment Resources, Lutz.

[19] Morris, J.C., Heyman, A. and Mohs, R.C. (1989) The Consortium to Establish a Registry for Alzheimer’s Disease. Part I: Clinical and Neuropsychological Assessment of Alzheimer's Disease. Neurology, 39, 1159-1165. http://dx.doi.org/10.1212/WNL.39.9.1159

[20] Watson, Y.I., Arfken, C.T. and Birge, S.J. (1993) An Objective Screening Test for Dementia. Journal of the American Geriatrics Society, 41, 1235-1240.

[21] Carolyn, M.B., Lisa, T.C., Tracy, M., Michelle, H., Alexander, W.D. and Dorothy, F.E. (2008) Reliability, Validity, and Clinical Utility of the Executive Function Performance Test: A Measure of Executive Function in a Sample of People with Stroke. American Journal of Occupational Therapy, 62, 446-455. http://dx.doi.org/10.5014/ajot.62.4.446

[22] Wolf-Peter, S., Andreas, R., Konrad, K., Karl-Heinz, L., Ralf, J. and Klaus, B. (2004) Functional and Cognitive Consequences of Silent Stroke Discovered Using Brain MRI in an Elderly Population. Journal of the American Geriatrics Society, 52, 7.

[23] Ballard, C., Stephens, S., Kenny, R.A., Kalaria, R., Tovee, M. and O’Brien, J. (2003) Profile of Neuropsychological Deficits in Older Stroke Survivors without Dementia. Dement Geriatric Cognitive Disorder, 16, 52-56. http://dx.doi.org/10.1159/000069994

[24] Stebbins, G.T., Nyenhuis, D.L., Wang, C., Cox, J.L., Freels, S., Bangen, K., de Toledo-Morrell, L., Sripathirathan, K., Moseley, M., Turner, D.A., Gabrieli, J.D. and Gorelick, P.B. (2008) Gray Matter Atrophy in Patients with Ischemic Stroke with Cognitive Impairment. Stroke, 39, 785-793. http://dx.doi.org/10.1161/STROKEAHA.107.507392

[25] Vataja, R., Pohjasvaara, T., Mäntylä, R., Ylikoski, R., Leppävuori, A., Leskelä, M., Kalska, H., Hietanen, M., Aronen, H.J., Salonen, O., Kaste, M. and Erkinjuntti, T. (2003) MRI Correlates of Executive Dysfunction in Patients with Ischaemic Stroke. European Journal of Neurology, 10, 625-631. http://dx.doi.org/10.1046/j.1468-1331.2003.00676.x

[26] Richard, H.S., Demetrios, J.S. and Sandra, E.B. (2003) Strategic Involvement of Cholinergic Pathways and Executive Dysfunction: Does Location of White Matter Signal Hyperintensities Matter? Journal of Stroke \& Cerebrovascular Diseases, 12, 29-36. http://dx.doi.org/10.1053/jscd.2003.5 